\title{
Trends and Fashions in Fruit Cultivar Production
}

Kim E. Hummer ${ }^{1}$ and Ed Stover ${ }^{2}$

\section{Introduction to the Workshop}

The market for fruit is experiencing extraordinary changes. Market consolidation has reduced the number of major retail channels and the needs of these large purchasers increasingly drive commodity production. At the same time, consumer affluence is driving demand for new, exciting, and top-quality produce. Globalization of markets, combined with ability to ship and store produce more effectively, mean there is no longer a "season" for most fruit. Other significant market forces are the emergence of convenience as a critical factor for routine consumption and a modest but significant demand for low-spray or organic produce. Each of these factors influences the development of new fruit cultivars and the choices that growers make when establishing new plantings.

This workshop presents views of cultivar usage and development in diverse fruit crops: citrus fruit (Citrus), stone fruit (Prunus), and blackberry (Rubus subgenus Rubus). Despite the diversity of crops, the following reports show commonalities in certain production concept paradigms:

- Extend commodity season to year-round production if possible.

- Improve the health benefits of the product.

- Eliminate undesirable characters.

- Diversify the crop types and available processed forms.

Although each crop approaches these precepts uniquely, they appear to have relevance across all fruit production.

EXTENDED SEASON. Until recently, fresh citrus was largely available only in the winter. During the last decade, global trade has provided opportunities for consumers to buy almost any fruit year-round, expanding the marketing season for citrus but also providing fruit that compete with citrus for winter sales. In stone fruits, protected culture and global transportation have expanded production zones. In berry crops, breeders are expanding the range to low-chill, high-temperature environments. They are actively developing lowchill types and cultivars that can be cropped consistently in tropical regions. Recent radical innovations in blackberry production, such as primocane fruiting, allow this plant to have two crops annually in temperate regions. Producers and marketers are trying to present the consumer with fruit on a year-round basis. Consumers seem willing to pay higher prices than usual for "out-of-season" produce.

IMPROVED HEALTH BENEFITS. Each of these fruit crops has healthful attributes. Antioxidant properties of the pigments in fruit have been shown to promote human nutrition and delay the onset of diseases and aging. Quantifying the nutritional effects, and encouraging production of these fruits in a manner that promotes human health and a clean environment, is a high priority for fruit cultivar research and development. In the minds of many, this

${ }^{1}$ U.S. Department of Agriculture-Agricultural Research Service, National Clonal Germplasm Repository, 33447 Peoria Road, Corvallis, OR 97333.

${ }^{2}$ Indian River Research \& Education Center, University of Florida, Ft. Pierce, FL 34945; current address: USDA/ARS, NCGR, One Shields Avenue, Davis, CA 95616. 
would include reduction in the use of agricultural chemicals and the increase in organic fruit production.

ELIMINATE UNDESIRABLE CHARACTERS; DEVELOP DESIRABLE ONES. The consumer desires convenience foods, easy to use, ready-to-eat products. Undesirable traits such as hard-to-peel skins or noticeably seedy fruits are unacceptable. Fresh-cut products that can be eaten on-the-go are in demand. Improved seedless mandarins (C. reticulata) are gaining wide popularity. In stone fruit, tree architecture is being modified by developing dwarfing rootstocks and reduced scion growth. New training systems for smaller, more precocious trees are increasingly used in many crops. Ripening systems are being examined for improved postharvest qualities. In blackberries, the thorniness of common native species and most cultivars is unacceptable for processed production, and thornless, sweet cultivars with sharp flavor are desired. Seeds must remain small and unnoticeable.

DIVERSIFY CROP TYPES AND PRODUCTs. The marketplace demands more products for gourmet and niche markets. Consumers want new and exciting flavors with high soluble solids and high sugar: acid ratios. For Citrus, not-from-concentrate juice is in heavy demand in the U.S., which in turn places pressures on growers for earlier and later ripening fruit. In peaches, pre-cut, minimally processed products are becoming successful. Blackberries are marketed fresh but new ways to market fresh-such as pick-your-own, farmer's markets, or on-farm sales-have increased.

\section{Conclusion}

Clearly, development and breeding of fruit cultivars depend on changing market pressures. Continuing demand for new cultivars is expected to be a major limitation on the economic life of many orchards. Private and public fruit breeding programs appear to be responding with a stream of new products that will meet the opportunities of the changing market. 